University of Nebraska - Lincoln

DigitalCommons@University of Nebraska - Lincoln

Faculty Publications, Department of Psychology

Psychology, Department of

October 2006

\title{
The Path to Licensure for Academic Psychologists: How Tough Is the Road?
}

\author{
David DiLillo \\ University of Nebraska-Lincoln, ddilillo@unl.edu \\ Sarah DeGue \\ University of Nebraska-Lincoln \\ Lee M. Cohen \\ Texas Tech University \\ Robert D. Morgan \\ Texas Tech University
}

Follow this and additional works at: https://digitalcommons.unl.edu/psychfacpub

Part of the Psychiatry and Psychology Commons

DiLillo, David; DeGue, Sarah; Cohen, Lee M.; and Morgan, Robert D., "The Path to Licensure for Academic Psychologists: How Tough Is the Road?" (2006). Faculty Publications, Department of Psychology. 119. https://digitalcommons.unl.edu/psychfacpub/119

This Article is brought to you for free and open access by the Psychology, Department of at DigitalCommons@University of Nebraska - Lincoln. It has been accepted for inclusion in Faculty Publications, Department of Psychology by an authorized administrator of DigitalCommons@University of Nebraska - Lincoln. 
Published in Professional Psychology: Research and Practice Vol. 37 (2006), No.5, pp. 567-586. http://www.apa.org/journals/pro/ Copyright (C) 2006 by the American Psychological Association. Used by permission. "This article may not exactly replicate the final version published in the APA journal. It is not the copy of record."

\title{
The Path to Licensure for Academic Psychologists: How Tough Is the Road?
}

\author{
David DiLillo and Sarah DeGue \\ University of Nebraska-Lincoln \\ Lee M. Cohen and Robert D. Morgan \\ Texas Tech University
}

\begin{abstract}
What obstacles are faced by academic psychologists seeking professional licensure? Data presented here from all U.S. jurisdictions suggests that licensure requirements vary greatly across states and in some areas may be quite difficult to fulfill within the context of an academic position. Results of a survey of training directors of clinical and counseling doctoral programs accredited by the American Psychological Association indicated that, although licensure is expected of most faculty, a number of challenges may impede this goal. Programmatic efforts to facilitate licensure of new faculty, as well as implications of our findings, possible remedies, and recommendations to new faculty, are presented.
\end{abstract}

Keywords: professional licensure, academic psychologist, psychology licensing board, rules and regulations

Since 1985, the number of states requiring supervised postdoctoral training for psychology licensure has increased from just over half to nearly $100 \%$ (see Stewart \& Stewart, 1998). Although the nature of postdoctoral requirements varies from state to state, nearly all jurisdictions call for (a) a minimum number of supervised training hours, (b) successful completion of the national Exam for the Professional Practice of Psychology (EPPP), and (c) the passing of additional state-specific oral and/or written exams. Regardless of the career path chosen, graduates may

David DiLillo received his $\mathrm{PhD}$ in clinical psychology from Oklahoma State University. He is currently an associate professor and director of the Clinical Psychology Training Program at the University of Nebraska-Lincoln. His research interests focus on various aspects of family violence, particularly the long-term impact of child maltreatment. He also maintains an interest in professional development and training issues.

Sarah DeGue will receive her PhD in clinical psychology from the University of Nebraska-Lincoln in 2006 after completing a clinical internship at the University of South Florida, Louis de la Parte Florida Mental Health Institute. Her dissertation research involved the development and comparison of predictive models of nonphysical and physical forms of male sexual offending against adult females. Her primary areas of research interest include predictors and correlates of sexual and family violence, forensic psychology, and mental health policy.

Lee M. Cohen received his $\mathrm{PhD}$ in clinical psychology from Oklahoma State University and completed his predoctoral internship in the Department of Psychiatry at the University of California, San Diego School of Medicine. $\mathrm{He}$ is associate professor and director of clinical training in the Department of Psychology at Texas Tech University. His research program systematically explores behavioral, cognitive, and physiological mechanisms that may contribute to nicotine use and dependence.

Robert D. Morgan received his PhD in 1999 from Oklahoma State University. He is associate professor of psychology and director of the American Psychological Association-accredited doctoral program in counseling psychology at Texas Tech University. His general research interests are in correctional mental health, forensic assessment, and professional development and training issues.

Correspondence concerning this article should be addressed to David DiLillo, 238 Burnett Hall, Lincoln, NE 68588-0308. E-mail: ddilillo@ unl.edu struggle to find postdoctoral experiences that will allow them to meet licensure requirements (Olvey, Hogg, \& Counts, 2002; Ryan $\&$ Chan, 1999). However, those seeking tenure-track positions in clinical or counseling psychology doctoral programs accredited by the American Psychological Association (APA) may encounter unique challenges in the pursuit of licensure. In the present article, we shed light on these issues.

\section{Why Should Academic Psychologists Be Licensed?}

From a legal perspective, academicians who supervise and train graduate students are in a position of responsibility regarding public welfare. Indeed, the principle of vicarious liability holds that psychologists acting as clinical supervisors are ultimately responsible for the actions of trainees (Knapp \& Vandecreek, 1997). In effect, then, unlicensed professionals in many jurisdictions may face restrictions against supervising therapeutic services provided by graduate student trainees. Moreover, because licensure signifies that one has attained the requisite knowledge and clinical experiences to function as an independent professional, faculty with this credential serve as particularly strong role models for graduate students. Consistent with this notion, the APA's guidelines for accreditation stress that faculty should obtain the "recognized credentials in those areas which are at the core of the program's objectives and goals" (APA Committee on Accreditation, 2005). Licensure also aids graduate training by permitting faculty who choose to engage in independent clinical practice to draw upon those experiences in the instruction and supervision of students.

\section{Challenges Along the Path}

Clearly, there are compelling reasons for academic psychologists to seek licensure. But what does the path to licensure hold for those who are academically bound? Specifically, can faculty satisfy the demands of licensure while simultaneously managing the rigors and responsibilities of a new tenure-track position? 
Olvey and colleagues (2002) documented the relatively high demands of psychology licensure in comparison to other professions. For instance, test preparation services recommend that candidates study for 200 to $300 \mathrm{hr}$ in order to pass the EPPP (Academic Review, 2005). Additional time must also be spent preparing for state written and oral exams. The financial costs associated with licensure, including various exam and licensure fees, can also be substantial. Aside from these challenges, the most significant hurdle for academics may be the widespread stipulation that postdoctoral experiences include a minimum number of client contact hours that must be accrued within a specific time frame during the prelicensure period. Such requirements can represent a serious obstacle for faculty, whose priorities revolve around research, teaching, and service activities and do not include the provision of direct clinical services (Cohen, Morgan, DiLillo, \& Flores, 2003). Although there has been general recognition of these issues (e.g., Association of State and Provincial Psychology Boards [ASPPB], 2003), one of our goals in the present study is to further illuminate these challenges by providing detailed information regarding the nature of postdoctoral licensing requirements across jurisdictions and how those requirements may impact the pursuit of licensure by entry-level faculty.

In addition to examining licensing criteria per se, a second goal of this study is to consider aspects of the academic environment (i.e., one's department and program) that may also have a bearing on achieving licensure (Cohen et al., 2003). For example. in spite of the advantages of licensure, it is unclear whether most APA-accredited training programs require or even encourage new faculty to become licensed. If licensure is expected, in what ways do programs facilitate this process for new faculty? On a related note, to what degree do training directors (TDs) perceive challenges faced by new faculty along the path to licensure? Finally, how often and to what extent is progress toward licensure figured into annual faculty evaluations? In this study, we addressed these questions through a survey of TDs, and in doing so, we shed light on unique issues and obstacles - and some advantages — faced by academic psychologists pursuing licensure.

\section{Criteria for Professional Licensure Across States}

To assess the variations in licensure requirements across the 50 states and District of Columbia, we gathered information from each jurisdiction detailing: (a) the amount (in hours) of postdoctoral experience required, (b) the time frame for completing postdoctoral training, (c) types of qualifying clinical activities, (d) the existence of any exemptions relevant to academic psychologists, and (e) the financial costs associated with licensure (see Appendix). The majority of this information was obtained from materials accessed via state board and legislative Web sites. We frequently used a Web site maintained by the University of Kentucky, College of Education (2005) and the Association of State and Provincial Psychology Boards (ASPPB, 2006), which contains links to individual state licensing boards, associations, and relevant statutes in the United States. We also conducted independent searches of state government sites when needed to obtain direct access to state rules, regulations, and laws governing licensure. Finally, when statutes or regulations were unclear, we used direct e-mail or telephone calls with state boards for clarification. We conducted these searches between
June 2004 and August 2005; all data in the Appendix are current as of January 2006.

\section{Postdoctoral Hours Required and Time Frame}

As shown in the Appendix, 48 states and Washington, DC, require some type of postdoctoral training experiences prior to licensure, with Alabama and Washington State being the exceptions. The modal number of hours is 1,500 ( $n=19$ states), with 43 states requiring between 1,500 and 2,000 hr. Of the remaining jurisdictions, two (Washington, DC, and Michigan) require 4,000 $\mathrm{hr}$, and four (Minnesota, Montana, South Dakota, and Texas) require that candidates acquire 1 year of postdoctoral experience but do not specify a minimum number of total hours.

The time frame permitted to accrue postdoctoral experiences varies across states. Several states specify that hours may not be acquired in less than a certain time period, presumably to prevent accrual of an inordinate number of hours in a short time frame. It is also common for states to specify a maximum allowable time for the accrual of hours. Almost half the jurisdictions allow a maximum of $2(n=12)$ or $3(n=11)$ years to obtain the required hours. On the high end of this category is Delaware, which permits a maximum of 6 years for university faculty to attain the needed hours. Many states $(n=18)$ indicated a minimum and maximum time period within which hours must be accrued, and a few $(n=3)$ stipulated that the training experiences must occur in consecutive months. Several states (Hawaii, Kansas, Maryland, Montana, New Jersey, North Dakota, Rhode Island, South Carolina, South Dakota, Vermont, and Wisconsin) specify minimum hour requirements but do not stipulate a time frame in which hours must be attained.

\section{Nature of Postdoctoral Activities}

Examination of the Appendix reveals that states differ widely in the degree to which they delineate the nature of the postdoctoral activities required. Several states $(n=18)$ specify a minimum number of hours or a proportion of total work time that must be devoted to direct client contact or service activities during the postdoctoral training period. Minimum hours requirements for states with this requirement range from 375 in Ohio and Arkansas to 1,000 in Nebraska and New Jersey. Among the states specifying activities as a proportion of work time is Alaska, which requires that at least $50 \%$ of the 1,500 mandated hours be "direct services" and that $50 \%$ of these "direct services" (375 hr) consist of faceto-face-contact with clients. Similarly, Pennsylvania mandates that $50 \%$ of the required $1,500 \mathrm{hr}$ consist of diagnosis, assessment, therapy, other interventions, or consultation. Other states indicate a minimum number of client contact hours that must be obtained on a weekly basis. For example, Missouri mandates that $10 \mathrm{hr}$ per week be devoted to direct clinical services. By contrast, several states provide relatively nonspecific guidelines for the types of activities required. Representative of this approach is Oklahoma, which requires that "postdoctoral experience shall be compatible with the knowledge and skills ... relevant to the intended area of practice" (Psychologists Licensing 1965/2004, p.7).

A total of 26 states specifically address whether typical academic activities may be counted toward licensure. Of these, several states (e.g., Arkansas, Connecticut, Illinois, Maine, Mary- 
land, Minnesota, Oklahoma, New York, South Dakota, Texas, and West Virginia) seem to place few or no limits on the amount of academically oriented activities that may be applied to licensure. Some of these states simply require postdoctoral activities to be commensurate with one's intended area of practice, whereas others make specific allowances for a large proportion of the postdoctoral hours to consist of research, teaching, and supervision. On the other hand, a smaller number of states specifically prohibit certain academic duties from counting toward licensure. Tennessee, for example, prohibits teaching and the provision of clinical services in the context of research from counting toward licensure at the health services provider level. Likewise, Oregon, South Carolina, and Utah are quite strict in that they prohibit time spent in research, teaching, or supervision from counting toward licensure. The remaining states place various limits on the type and/or quantity of academic duties that are permissible. For example, Kentucky stipulates that for those in academic settings, at least 400 of the 1,800 total hours must consist of "direct or indirect supervised client involvement, including supervising student clinical work, diagnosis and interviewing as part of clinical research projects, and clinical work in the context of teaching psychotherapy, interviewing, or testing" (Kentucky Administrative Regulations, n.d., p. 36). Similarly, Ohio allows up to $30 \%$ of the required $1,800 \mathrm{hr}$ to consist of teaching and/or research if the activities have a direct effect on client welfare or involve client contact. Colorado allows research and teaching to each be counted for $500 \mathrm{hr}$ of the required 1,500 postdoctoral hours, with supervision of graduate student research and/or clinical work counting toward the allotted $500 \mathrm{hr}$ of teaching. Finally, regulations in three states (California, Louisiana, and North Dakota) mention the possibility of special provisions regarding acceptable postdoctoral activities for academic psychologists but do not specifically spell these out. California regulations, for instance, state that "trainees accruing hours in areas of psychology that do not include direct mental health services may establish an 'alternate plan' for the supervised professional experience" (Regulations Relating to the Practice of Psychology, 2005, p. 62).

\section{Supervision Requirements}

The Appendix also depicts variations in supervision requirements across states. Most states $(n=39)$ state that some or all of the supervision received must be "face-to-face," with the most common requirement being that candidates receive at least $1 \mathrm{hr}$ of individual in-person supervision per week. One state (Nebraska) permits either face-to-face or interactive video supervision. Several jurisdictions specify a more stringent ratio of supervision per time worked. For example, 14 states (Arizona, Florida, Idaho, Kansas, Minnesota, Mississippi, New York, North Dakota, Oregon, Pennsylvania, Vermont, Virginia, West Virginia, and Wyoming) require on the order of $1 \mathrm{hr}$ of supervision per $20 \mathrm{hr}$ worked. Among the states with the most stringent requirements are Connecticut, which requires either 3 or $4 \mathrm{hr}$ of weekly supervision (depending on employment setting), and Maine, which mandates $3 \mathrm{hr}$ of supervision per week, $1 \mathrm{hr}$ of which must be individual face-to-face; Delaware requires 1 supervision $\mathrm{hr}$ for every 1 to $10 \mathrm{hr}$ worked per week, whereas New Jersey stipulates 4 hr of supervision for every 20 client contact hours, half of which must be face-to-face.

\section{Exemptions}

The second-to-last column in the Appendix summarizes licensure exemptions relevant to academic psychologists. Although the precise wording varies, these exemptions fall into three main categories. First, from a total of the 45 jurisdictions ( 44 states and Washington, DC) providing relevant exemptions, 28 indicate that academic psychologists need not be licensed in order to perform their usual job duties, provided that these activities occur within the confines of their institution. Thus, in a large number of cases, licensure is not needed to perform typical teaching, research, and training duties, presumably including the clinical supervision and training of graduate students. By contrast, 14 states specifically exempt research and teaching but not clinical supervision or direct services, indicating that licensure is required to perform these latter duties. Finally, three jurisdictions (New Hampshire, Virginia, and Washington, DC) permit unlicensed individuals in academic settings to supervise clinical work provided that they are themselves supervised by a licensed psychologist.

\section{Financial Costs}

As with other criteria, the costs associated with licensure vary significantly across states. The final column in the Appendix reflects the sum of any application fees, state oral and written exam fees, and license or processing fees required at the time of first licensure. Additional costs unique to certain states are also included in this figure (e.g., Nevada charges a \$25 license printing fee). These figures do not include costs associated with the EPPP, which range from $\$ 350$ in New Jersey to $\$ 532$ in California. Wyoming costs include the actual exam fee payable to the Professional Examination Service plus a $20 \%$ administrative fee.

\section{Programmatic Factors Related to Licensure: Survey of TDs}

We developed a questionnaire to gather information from TDs regarding programmatic factors that may impact the licensure process for tenure-track faculty. TDs were selected because as the directors of professional programs, they are well aware of licensure issues, are typically licensed themselves, and are responsible for programmatic issues related to APA accreditation. Furthermore, as experienced faculty, they are aware of departmental policies and expectations for junior faculty. We used the questionnaire to assess programmatic expectations that faculty become licensed, reasons for requiring faculty licensure (if applicable), perceptions regarding the feasibility and challenges associated with faculty pursuit of licensure, departmental facilitation of the licensure process, and whether progress toward licensure is figured into faculty evaluations.

TDs at each of the 294 APA-accredited clinical $(n=219)$ and counseling $(n=75)$ psychology doctoral programs in the United States and Canada were invited to complete the survey described above via a personalized e-mail containing a direct hyperlink to the study Web site. Approximately 1 week after initial contact, we sent a second e-mail invitation to participate to those who had not responded. We mailed a single postcard invitation 1 to 2 weeks after that to TDs who had not yet completed the survey. Finally, we also posted solicitations to participate on three training director listservs. 
The above procedures yielded responses from a total of 147 TDs of APA-accredited programs, for a total response rate of $50 \%$. This overall rate included TDs from 112 clinical and 35 counseling psychology training programs in the United States. This level of participation is comparable to that reported in other surveys of TDs (e.g., Vacha-Haase, Davenport, \& Kerewsky, 2004). Response rates were similar for clinical versus counseling (51\% vs. 46.7\%) and $\mathrm{PhD}$ versus PsyD (49\% vs. 55.6\%) TDs. Examination of response patterns revealed no obvious biases, either geographical or by type of institution (i.e., university, professional school), among the responding programs.

\section{Results of TD Survey}

TD responses regarding programmatic expectations, challenges, and facilitation for new faculty seeking licensure are described below and presented in Table 1. This table presents the combined results for all responding programs as well as percentages broken down by program type, with chi-square comparisons presented between clinical and counseling $\mathrm{PhD}$ programs and between $\mathrm{PhD}$ and PsyD programs.

\section{Expectations for Licensure}

To assess variations in expectations for new faculty licensure, we asked TDs whether obtaining licensure was encouraged, required, or not expected within their training program. Results indicated that $85 \%$ of the training programs either encouraged $(n$ $=69,46.9 \%)$ or required $(n=56,38.1 \%)$ new faculty to become licensed once employed. PsyD programs were more likely than $\mathrm{PhD}$ programs to require licensure prior to employment $(23.3 \%$ vs. $1.7 \%)$ or once hired $(53.3 \%$ vs. $34.2 \%)$, whereas $\mathrm{PhD}$ programs were more likely than PsyD programs to encourage licensure $(53 \%$ vs. $23.3 \%)$ or have no expectation for licensure $(11.1 \%$ vs. none), $\chi^{2}(3, N=147)=28.34, p<.01$.

The most common reasons provided by TDs for encouraging or requiring licensure by new faculty were related to the supervision and training of graduate students $(83.7 \%)$. In addition, TDs indicated that retaining APA accreditation (61.2\%), being consistent with the scientist-practitioner model (55.1\%), and improving their program's reputation $(39.5 \%)$ were also important factors. Reasons provided by TDs for encouraging or requiring licensure varied by program type. For example, in comparison to clinical TDs, counseling TDs more often cited retaining APA accreditation $(78.8 \%$ vs. $52.4 \%), \chi^{2}(1, N=117)=6.87, p<.05$, and improving their program's reputation $(63.6 \%$ vs. $26.2 \%), \chi^{2}(1, N=$ $117)=14.29, p<.01$, as reasons for encouraging or requiring licensure. Furthermore, PsyD programs were more likely than $\mathrm{PhD}$ programs to encourage or require faculty licensure in order to serve as better role models for students $(18.2 \%$ vs. $1.7 \%), \chi^{2}(1$, $N=138)=12.04, p<.01$; to pursue clinical work or independent practice $(16.7 \%$ vs. $.9 \%), \chi^{2}(1, N=140)=14.42, p<.01$; or to maintain their professional identity and credibility $(10 \% \mathrm{vs}$. $0.9 \%) \chi^{2}(1, N=147)=7.54, p<.05$.

\section{Challenges to Obtaining Licensure}

TDs were asked to report whether professional licensure was attainable for full-time faculty in their program. Less than a fourth of respondents $(22.9 \%)$ indicated that obtaining licensure was easily possible for new full-time faculty, whereas $68.6 \%$ indicated that it was possible with difficulty. A few TDs reported that licensure was not possible for faculty in their program $(6.1 \%)$, and a small number were not sure $(4.8 \%)$. No significant differences were found between program types in terms of expectations for licensure.

TDs cited several specific obstacles facing new faculty in their programs that may make licensure difficult or impossible to achieve. These included the inconsistency of this task with their current job duties $(62.6 \%)$, limited time for studying $(43.5 \%)$, financial difficulties (19.7\%), and a lack of resources (e.g., study materials; 7.5\%). Although a large majority of TDs from $\mathrm{PhD}$ programs $(70.1 \%)$ indicated that licensure requirements are inconsistent with their job duties, only a third from PsyD programs $(33.3 \%)$ reported this as an issue, $\chi^{2}(1, N=147)=13.8, p<.01$. Results also showed a perception by TDs that faculty in counseling $\mathrm{PhD}$ programs, compared with clinical $\mathrm{PhD}$ programs, have more difficulty finding time to study $(69.7 \%$ vs. $34.5 \%), \chi^{2}(1, N$ $=117)=11.87, p<.01$, and obtaining the resources necessary to prepare for the licensure exam $(30.3 \%$ vs. none $), \chi^{2}(1, N=117)=$ $27.83, p<.01$.

\section{Program Facilitation of Licensure}

Training programs varied in the type and amount of assistance provided to new faculty seeking licensure. In the majority of cases, supervision of clinical activities was provided by licensed faculty in the department (55.8\%). In fact, ready access to supervision may be an advantage of seeking licensure within an academic setting. Many programs (40.1\%) also permitted the use of a departmental clinic to acquire needed clinical hours. However, this was more common in clinical $\mathrm{PhD}(48.8 \%)$ than counseling $\mathrm{PhD}(27.3 \%)$ training programs, $\chi^{2}(1, N=117)=4.5, p<.05$. Some programs also provided course releases $(12.9 \%)$ and financial assistance for licensure-related costs $(18.4 \%)$ in order to facilitate new faculty licensure.

Although supervision was more often provided by departmental faculty, the use of outside supervisors was not unusual $(31.3 \%)$. When licensed faculty provided supervision, $89.9 \%$ of the time the unlicensed faculty members were not expected to pay for this service. Finally, less than a third (29.3\%) of training programs overall considered progress toward licensure in annual evaluations for junior faculty. However, this figure was considerably higher for PsyD than for PhD programs (56.7\% vs. 22.2\%), $\chi^{2}(1, N=117)=13.69, p<.01$.

\section{Summary of Training Director Comments}

One third of participating TDs $(n=49)$ provided general comments following completion of the questionnaire. The majority seemed to feel that the survey raised important questions regarding the licensure of academics. Many TDs commented on licensure laws in specific jurisdictions and/or how their programs had dealt with the issue of faculty licensure. For example, some TDs noted that requirements in their state permit the duties associated with a full-time academic position (e.g., research, teaching, and so forth) to count toward licensure hours, thereby resolving many of these issues for new faculty. On the other hand, a few respondents indicated that the licensure re- 
Licensure for AcAdemic Psychologists

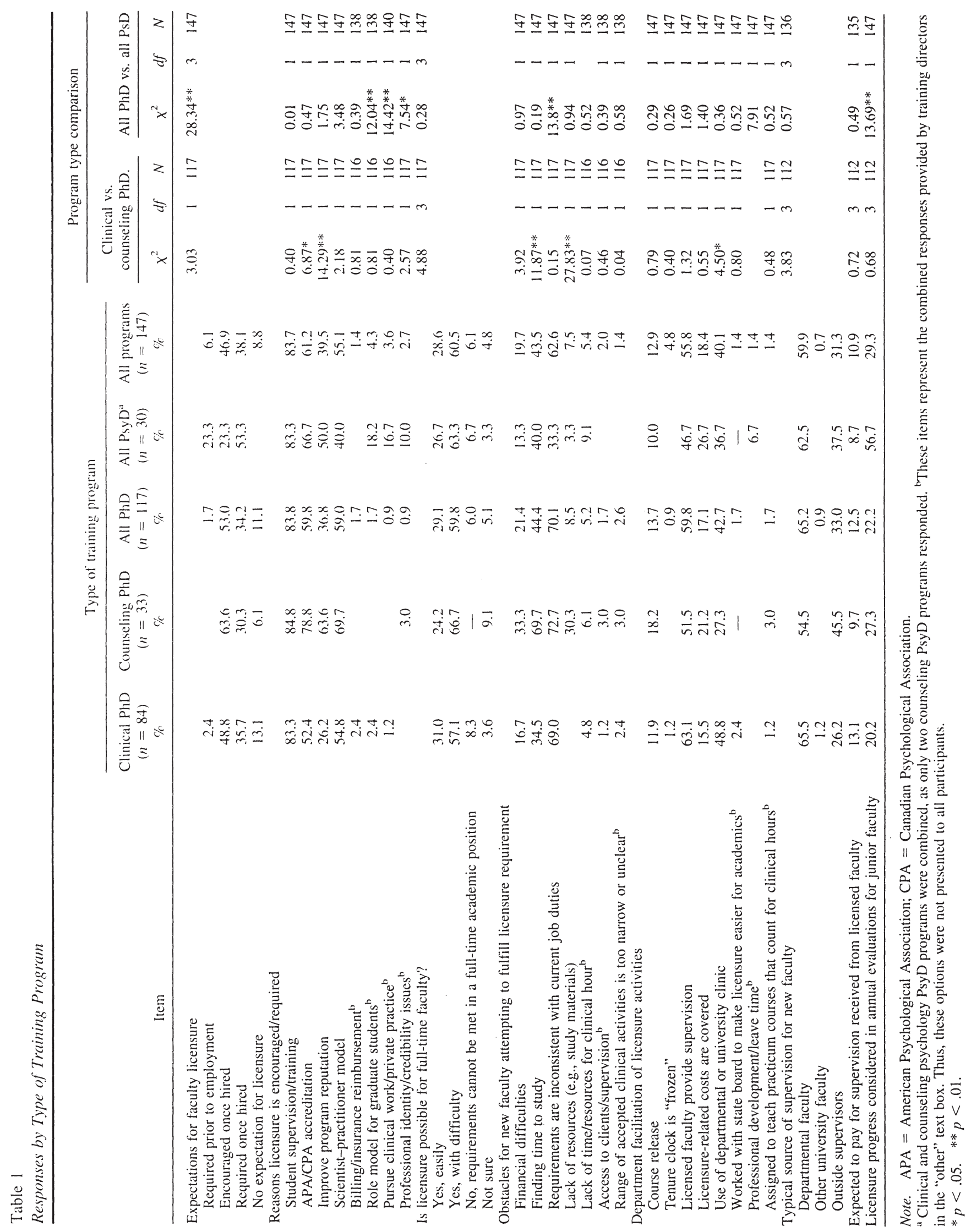


quirements in their state were such that obtaining the necessary hours as a tenure-track faculty member was "overwhelming" or "not possible." A total of 10 TDs commented that their programs only hire faculty who are already licensed or "license-eligible." A TD from one clinical PsyD program indicated that this stance toward licensure developed recently in response to the difficulties faced by past hires who found it difficult to obtain the necessary clinical hours, find affordable supervision, and study for the licensure exam while in their full-time position. A clinical $\mathrm{PhD}$ program TD noted that the strongest candidates for academic positions have often had research-focused postdoctoral experiences and are lacking the clinical hours necessary for licensure. This TD suggested the possibility that a policy of favoring licensed or license-eligible applicants may result in the program's loss of qualified individuals.

A number of TDs suggested possible solutions to the challenge of licensure for academic psychologists. One respondent stated that several faculty members approached the state licensing board with these issues and requested an extension of the time limit for obtaining postdoctoral clinical hours from 12 to 36 months. This extension was granted, and since that time, the TD reported that new faculty members have not had problems obtaining licensure. Another clinical PhD program TD alluded to recent efforts on the part of the Council of University Directors of Clinical Psychology to encourage APA to recommend dropping the requirements for supervised postdoctoral hours prior to licensure. This TD also voiced support for legislation to make licensure contingent upon total supervised clinical hours, such that students who have accumulated sufficient hours during their graduate training and predoctoral internship would be eligible to take examinations for licensure without additional postdoctoral work.

\section{Discussion and Recommendations}

\section{Impact of State Regulations on the Licensure of Academics}

Clearly, licensure requirements vary considerably across states (see the Appendix), resulting in differing levels of complexity associated with obtaining professional licensure. At one end of the continuum are those states with regulations that seem compatible with typical academic duties. Regulations in these states reflect an assumption that the practice of psychology includes teaching, research, and supervision, and that postdoctoral experiences should coincide with one's eventual area of professional work. On the other end of the spectrum are jurisdictions that mandate substantial amounts of direct client services. Although the specific amounts vary, the increased levels of client contact hours required in these states represent a larger hurdle to licensure for academics. The cumulative time needed to meet requirements in these states could amount to a day or more per week - a potentially insurmountable challenge for new faculty, whose progress toward tenure is dependent upon other types of activities. Thus, in a number of jurisdictions, the path to licensure appears to be quite a tough road indeed.

\section{Programmatic Factors Related to Licensure}

Results of the TD survey shed light on the professional environments in which the various state licensure requirements must be met. Although the vast majority of training programs $(85 \%)$ either encourage or require new faculty to obtain professional licensure once hired, relatively few programs require the credential prior to starting employment $(6.1 \%)$ or have no expectation that licensure be pursued $(8.8 \%)$. With the exception of PsyD programs, which more often require licensure prior to employment, these findings were fairly consistent across program type and support the notion that new academics often find themselves in the position of pursuing licensure while simultaneously meeting the demands of a tenure-track position. Although the most common reason noted by TDs for encouraging or requiring licensure was related to the supervision and training of graduate students, differences in program types suggest that counseling programs are more concerned with how others will view their training program (e.g., overall reputation, APA accreditation) than are clinical TDs. PsyD programs appear to focus more on having faculty who represent professionally balanced role models.

Despite the consistent expectation that faculty become licensed, less than $30 \%$ of TDs believed that obtaining licensure was easily possible. A similar percentage of PhD and PsyD TDs felt that obtaining licensure was easily possible (29\% vs. $27 \%$ ), which may reflect comparable challenges for program types in various jurisdictions. However, the majority of TDs across program type $(61 \%)$ believed obtaining licensure as a new faculty member to be possible with difficulty. The main reasons reported for this difficulty revolved around new faculty not having the time to fulfill requirements while in the midst of their academic responsibilities. $\mathrm{PhD}$ programs were more likely to note time constraints and cost issues than were their PsyD counterparts; however, PsyD TDs were more likely than their $\mathrm{PhD}$ colleagues to mention lack of resources for clinical hours as a deterrent. This finding is surprising given the earlier indication that PsyD programs more often emphasize a professional balance compared with their PhD counterparts.

The most common programmatic means of facilitating licensure are the use of departmental clinics for clinical activities and the availability of postdoctoral supervision by licensed faculty. In fact, ready access to clients and supervision appears to be an advantage of seeking licensure within an academic setting. Clinical $\mathrm{PhD}$ programs more often allow faculty the use of departmental clinics to acquire hours toward licensure. At first glance this may seem counterintuitive given the more supportive stance taken by counseling $\mathrm{PhD}$ programs noted above. However, this difference may be because counseling programs more often rely on university counseling centers rather than in-house clinics as a source of client contact. Regarding other types of assistance, course releases and financial support for licensure expenses are relatively uncommon, although counseling $\mathrm{PhD}$ programs are more likely to provide such resources. Finally, even though TDs consistently reported that new faculty are expected to become licensed and acknowledged the difficulty in doing so, with the exception of PsyD programs, relatively few departments (approximately 25\%) officially consider progress toward licensure as part of annual faculty evaluations. This suggests that many pretenure faculty must meet expectations that they complete the time-consuming licensure process (perhaps at the expense of research and teaching duties) yet are not able to receive formal "credit" for these efforts. 


\section{Training Implications}

If, as suggested here, academic psychologists in several jurisdictions face nearly insurmountable hurdles to licensure, then it is important to consider the implications of these findings for graduate student training. In scientist-practitioner programs, lack of faculty licensure may sharpen the divide between research and practice, for example, by necessitating the farming out of clinical supervision to outside professionals. The resulting division is inconsistent with the scientist-practitioner ideal of training by professionals who embody the integration of empirical and clinical perspectives. Licensure seems equally critical to programs operating from a practitioner-scholar perspective, which places even more emphasis on the clinical aspects of the profession. Within this model, lack of faculty licensure runs counter to the crucial programmatic goal of training clinicians. Finally, although the clinical-scientist model places relatively greater emphasis on the research aspects of the profession, faculty licensure nevertheless facilitates student training in the use of empirically informed interventions, which remains an integral component of this training model.

\section{Impact of Exemptions}

Before discussing ways to alleviate the licensure dilemmas highlighted here, it seems important to consider the impact of exemptions. Most notable are the 28 states that offer exemptions for typical academic job duties. Faculty may benefit from these exemptions because they are able to engage in clinically related teaching, research, and training activities without being licensed. However, a potential downside of releasing faculty from the need for licensure is that this may discourage them from pursuing activities not covered by exemptions, such as outside clinical work or contracts that require licensure and could ultimately enhance student training experiences. On a related note, to the extent that licensure conveys professional competence and a comprehensive, integrated training background, faculty without this credential may be seen as less capable role models by graduate student trainees.

\section{Possible Remedies and Recommendations to New Faculty}

In response to broader concerns about the impact of postdoctoral licensing requirements on the profession, APA's Commission on Education and Training Leading to Licensure was charged with evaluating the nature and quality of training in psychology (Williams-Nickelson, n.d.). This group determined that 2 years of supervised clinical training can be sufficient to develop the competencies needed by entry-level psychologists. It is important to note that the group concluded that one of these years could consist of predoctoral practicum-related activities, provided such experiences are sequential, organized, and well supervised; the second year would consist of the usual predoctoral internship. Thus, under certain conditions, the commission recommended eliminating altogether the requirement for formal postdoctoral training. One rationale for this recommendation was an assertion that the quality and quantity of preinternship clinical training has increased substantially in recent years, thereby reducing the need for formalized postdoctoral training. Consistent with this notion, the APA Council of Representatives re- cently adopted a policy change that would alter the 1987 Model Act for State Licensure of Psychologists (APA, 1987) in order to allow the 2-year supervised clinical experience to be completed as part of graduate training. This modification was opposed by most member jurisdictions of the ASPPB (S. DeMers, personal communication, March 8,2006 ) as well as by the Association of Psychology Postdoctoral and Internship Centers (S. McCutcheon, personal communication, March 8, 2006). Among other objections, these organizations questioned whether practicum experiences currently provide the type and amount of training needed for licensure. To date, only Washington State has made changes to eliminate postdoctoral requirements. Thus, although the revised APA policy may eventually be an impetus for advocating change at the state level, it is too early to tell what the implications of these recommendations will be. Regardless, any push to eliminate postdoctoral requirements through regulatory action at the state level could impact other issues important to the field. For example, if such initiatives are viewed by lawmakers as an attempt to relax training standards, this could open unwanted debate on a host of related issues, including scope of practice, hospital privileges, third-party reimbursement, and qualifications for prescriptive authority.

A less drastic alternative that could benefit academic psychologists would be to promote regulations that make the attainment of postdoctoral supervised experiences feasible for faculty in all locations. As demonstrated by the present data, faculty in a number of jurisdictions face potentially insurmountable obstacles to licensure. In recognizing this dilemma, the ASPPB's Guidelines for Supervision of Doctoral Level Candidates for Licensure (ASPPB, 2003) recommend that academic psychologists be permitted to spend up to $80 \%$ of a proposed $1,500 \mathrm{hr}$ postdoctoral training period in research and/or teaching activities, with the remaining $20 \%$ devoted to direct clinical services or clinical supervision. This requirement not only seems attainable, but also is based on the logical notion that the purpose of licensure - to protect consumers of psychological services - is best served when postdoctoral training activities are commensurate with one's intended area of practice (ASPPB, 2003). Widespread adoption of this recommendation could go a long way toward alleviating the challenges to licensure faced by academics in a number of states.

Until such time that broader systemic changes are implemented, individual faculty and departments will be left to address licensing issues within the bounds of existing regulations. For new faculty, this necessitates having a clear understanding of departmental expectations for licensure as well as the licensing requirements in any state of potential employment. The feasibility of meeting requirements while maintaining other academic responsibilities should be explicitly discussed with departmental leadership prior to hiring. The current findings show that most departments expect faculty to become licensed but may also be willing to support this process in various ways. Hence, job candidates should inquire about the possibility of departmental assistance, including the use of training clinics, supervision from senior faculty, course releases, and financial assistance to cover licensure expenses. If licensure is expected, new faculty should clarifyand perhaps negotiate - whether their progress will be included as a formal component of annual evaluations. Part of this process might include educating the hiring department about the challenges associated with the licensure process. After all, depart- 
ments and programs that recognize not only the advantages of having licensed faculty, but also the burdens of the process will be most likely to support junior colleagues along the path. Finally, once hired, academic psychologists should stay apprised of licensure-related issues in their respective jurisdictions. Regulations can change quickly, and by staying informed, faculty will be in the best position to affect matters that are most pertinent to their professional well-being.

\section{References}

Academic Review. (2005). Frequently asked questions. Retrieved July 28, 2005, from http://www.areview.com/ProgramDesc. asp?Lic $=$ PW\&Key $=\mathrm{f} \& \mathrm{~m}=\mathrm{m}$

American Psychological Association. (1987). Model Act for State Licensure of Psychologists. American Psychologist, 42, 696703.

American Psychological Association, Committee on Accreditation. (2005). Guidelines and Principles of Accreditation of Programs in Professional Psychology. Retrieved July 28, 2005, from http://www.apa.org/ed/G\&Po52.pdf

Association of State and Provincial Psychology Boards. (2003). Guidelines for supervision of doctoral level candidates for licensure. Retrieved July 18, 2005, from http://www.asppb. org/

Association of State and Provincial Psychology Boards. (2006). Licensing boards contact information. Retrieved May 3, 2006, from http://www.asppb.org/about/boardContactStatic.aspx

Cohen, L. M., Morgan, R. D., DiLillo, D., \& Flores, L. Y. (2003). Why was my major professor so busy? Establishing an academic career while pursuing applied work. Professional Psychology: Research and Practice, 34, 88-94.

Kentucky Administrative Regulations 201 § 26:190. (n. d.). Retrieved May 3, 2006, from http://finance.ky.gov/NR/rdonlyres/D00A6938-E115-4FB1-A60E-9FB730BA296C/0/lawa- ndregulations.\%20.pdf

Knapp, S., \& Vandecreek, L. (1997). Ethical and legal aspects of clinical supervision. In C. E. Watkins (Ed.), Handbook of psychotherapy supervision (pp. 589-599). New York: Wiley.

Olvey, C. D., Hogg, A., \& Counts, W. (2002). Licensure requirements: Have we raised the bar too far? Professional Psychology: Research and Practice, 33, 323-329.

Psychologists Licensing Act. 59 Okla Stat $\S 1362.2$ (1965 amended 2004). Retrieved May 3, 2006, from http://www.ok.gov/OSBEP/documents/Psych\%\%2020Lic\%2 0Act $\% 202004 \% 20$ for $\% 20$ mailing.pdf

Regulations Relating to the Practice of Psychology California 16 $\S 1387$ 2005. Retrieved May 3, 2006. from http://www.psychboard.ca.gov/laws_regs/laws_regs.pdf

Ryan, A. M., \& Chan, D. (1999). Perceptions of the EPPP: How do licensure candidates view the process? Professional Psychology: Research and Practice, 30, 519-530.

Stewart, A. E., \& Stewart, E. A. (1998). Trends in postdoctoral education: Requirements for licensure and training opportunities. Professional Psychology: Research and Practice, 29, 273-283.

University of Kentucky, College of Education. (2005). 50 states and U.S. territories licensure. regulations. associations and boards. Retrieved May 3, 2006, from http://www.uky.edu/Education/EDP/psyinfo2.html

Vacha-Haase, T., Davenport, D. S., \& Kerewsky, S. D. (2004). Problematic students: Gatekeeping practices of academic professional psychology programs. Professional Psychology: Research and Practice, 35, 115-122.

Williams-Nickelson, C. (n.d.). Outcome of the Commission on Education and Training Leading to Licensure in Psychology: Impact and implications for students and new psychologists. Retrieved December 31, 2005, from http://www.apa.org/ apags/edtrain/comontrain.html 


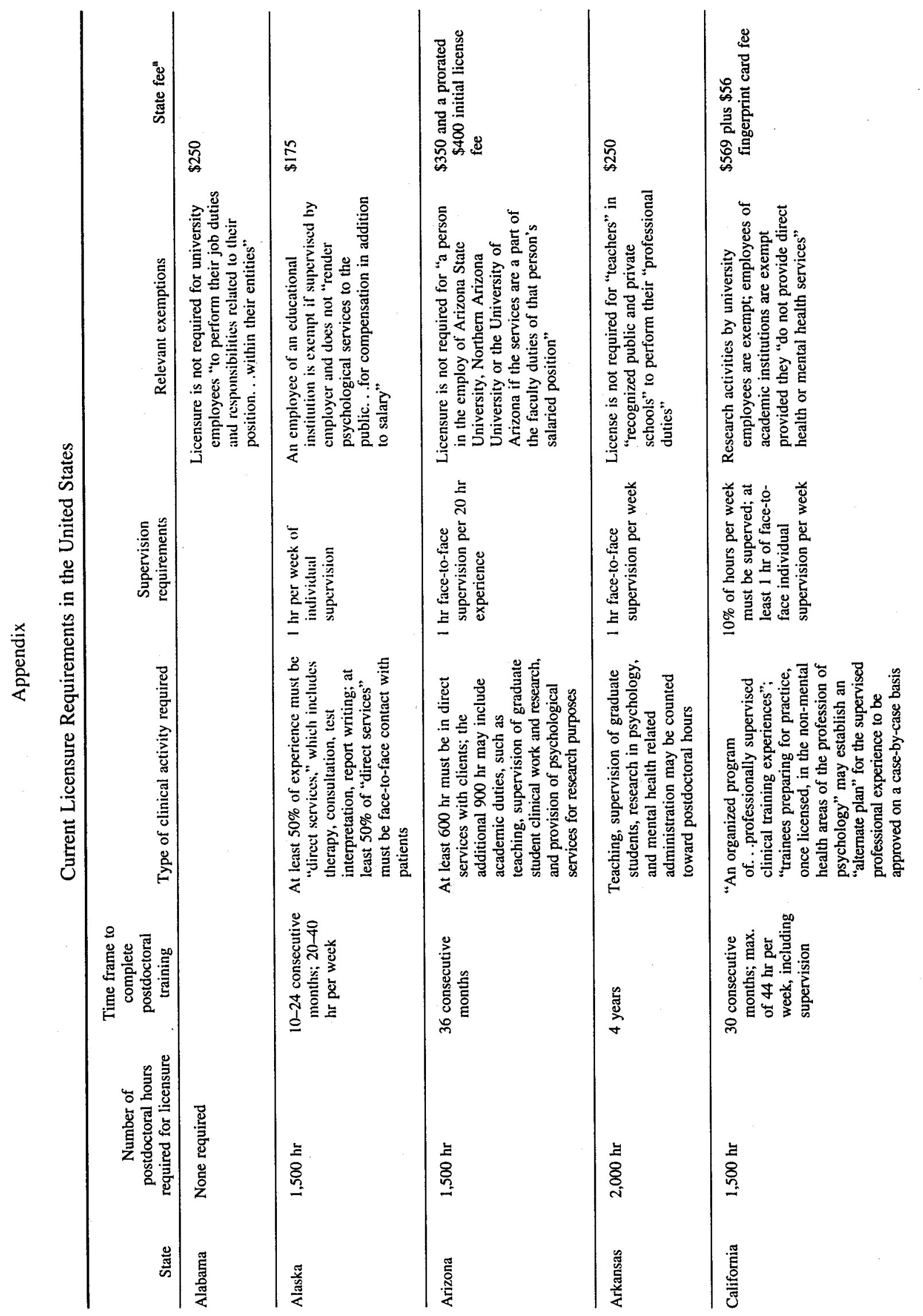




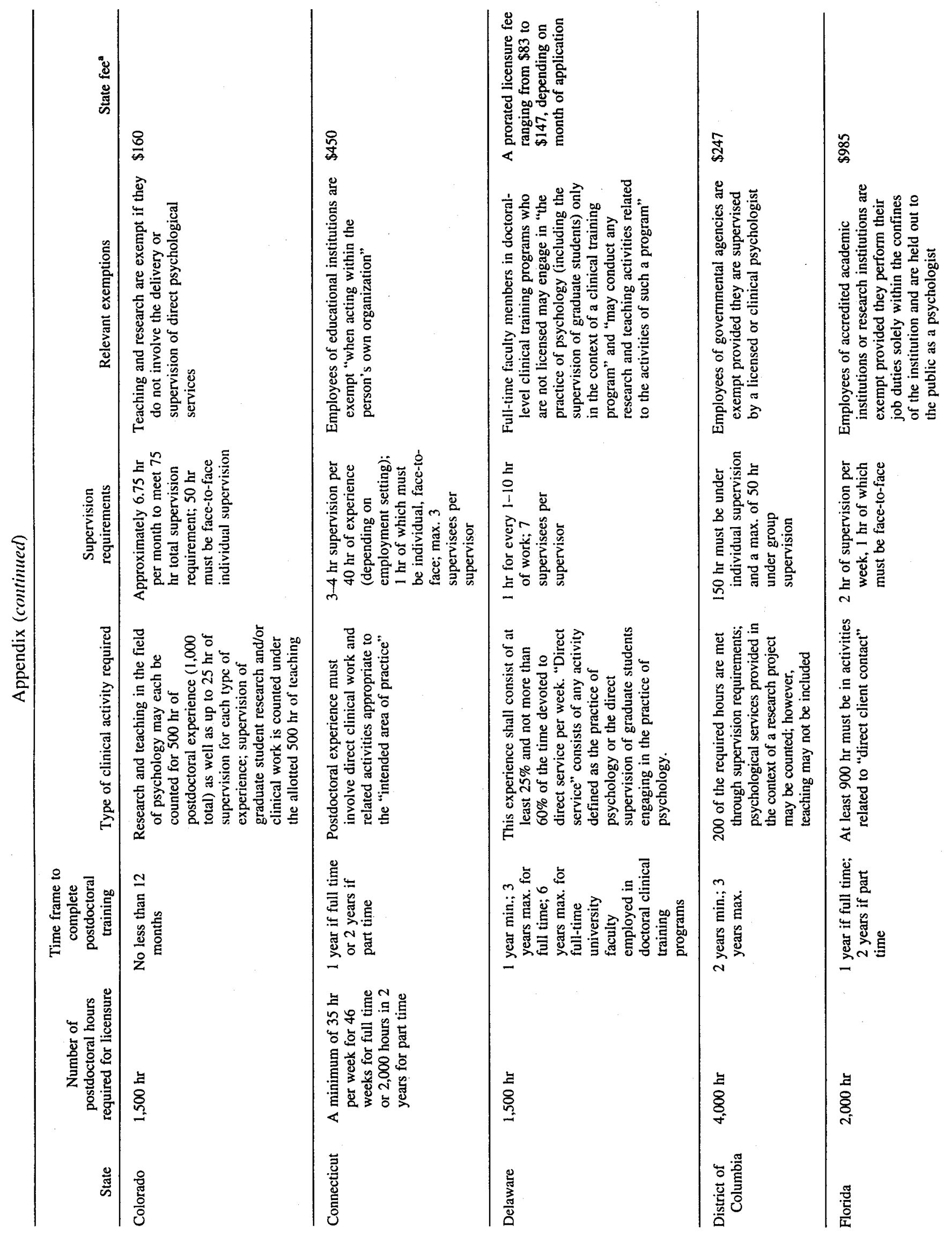




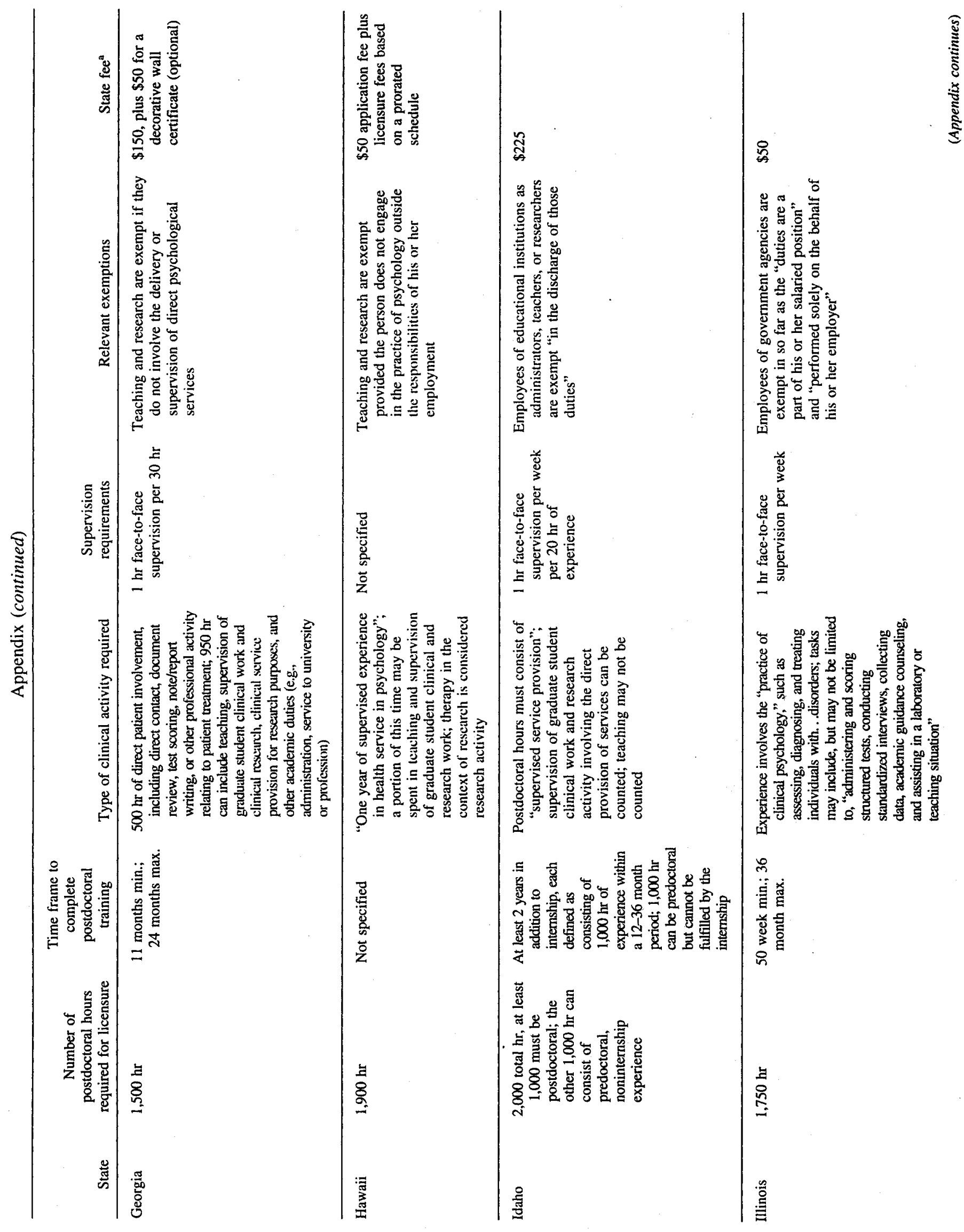




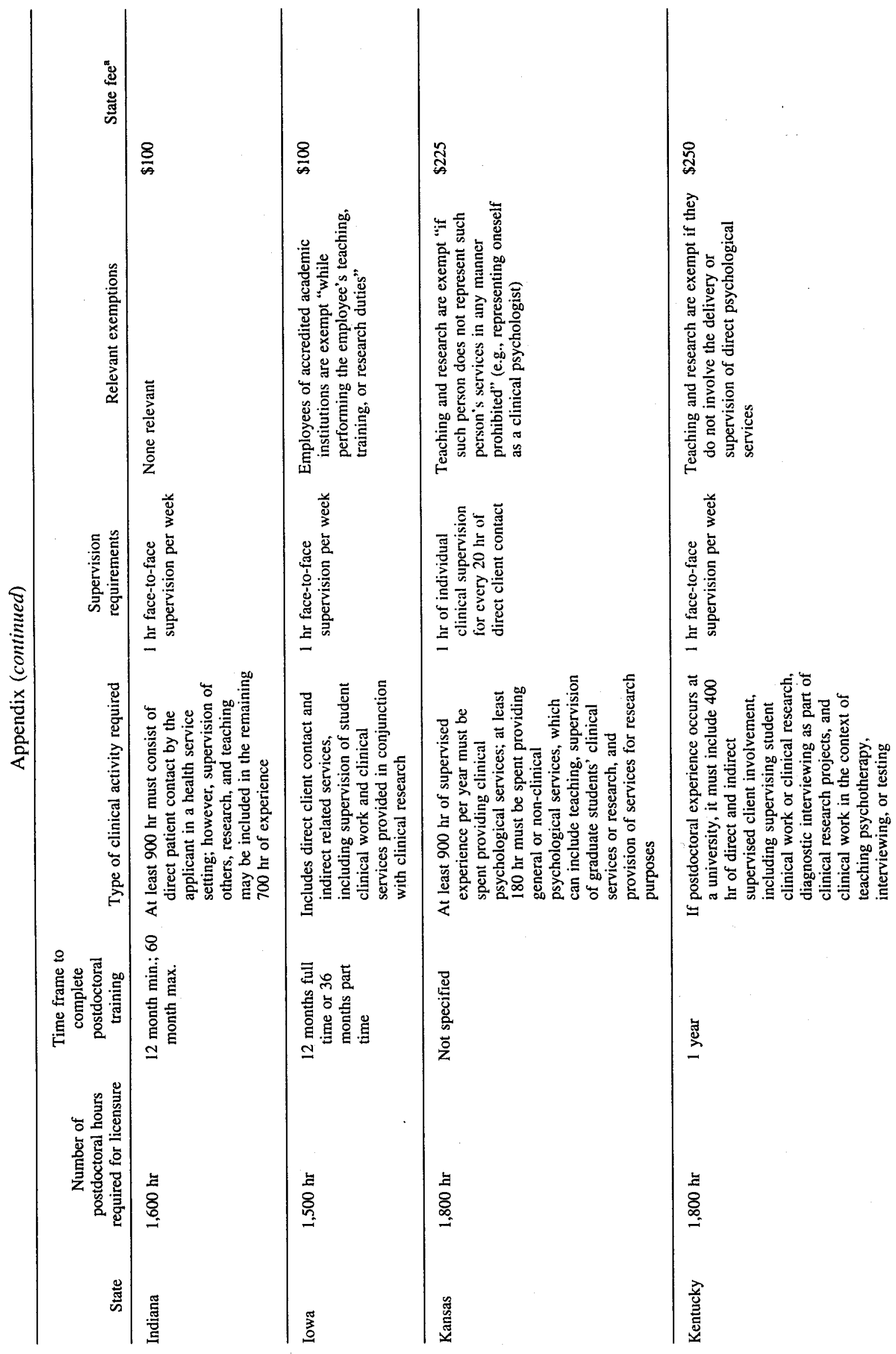




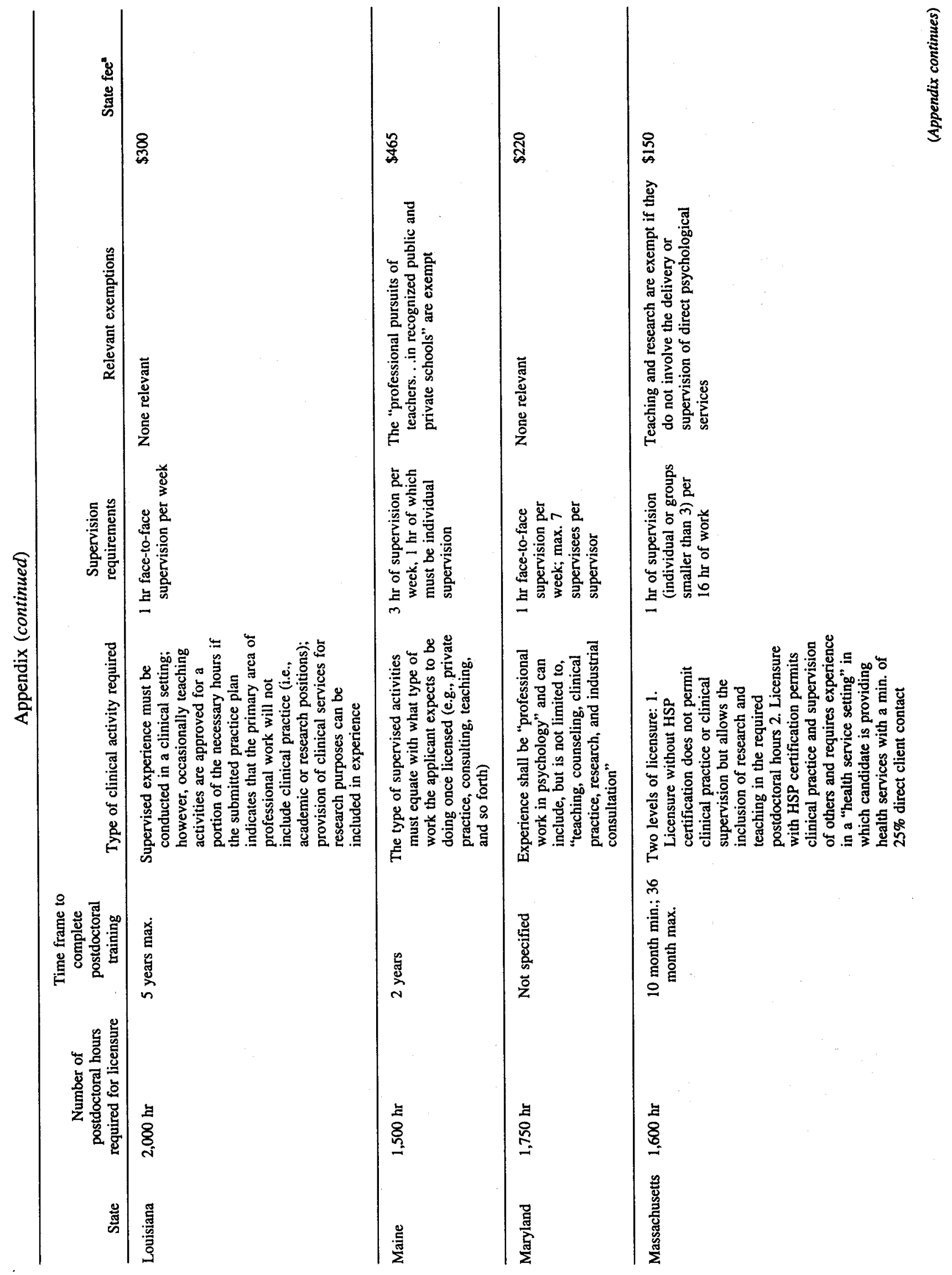




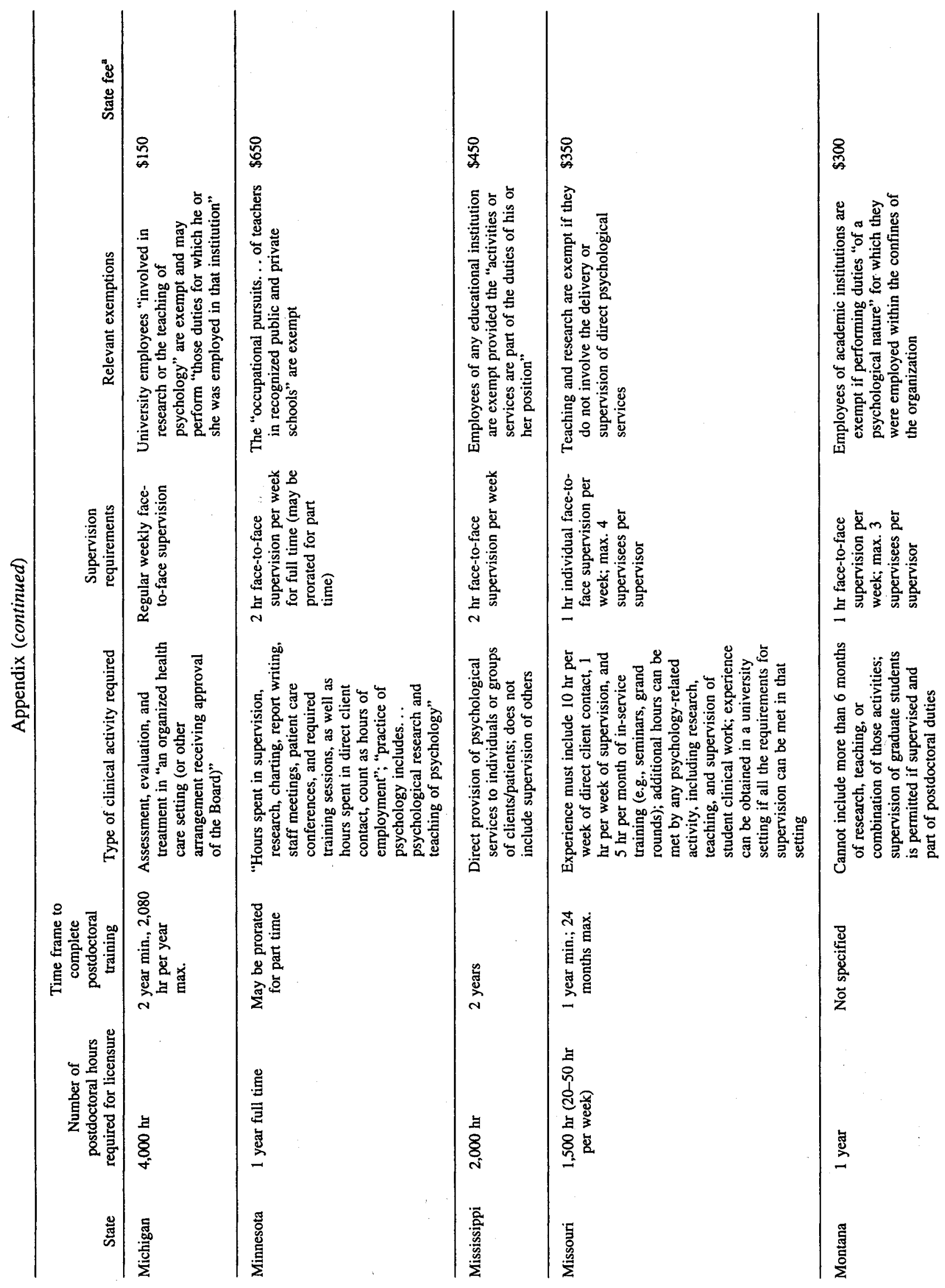




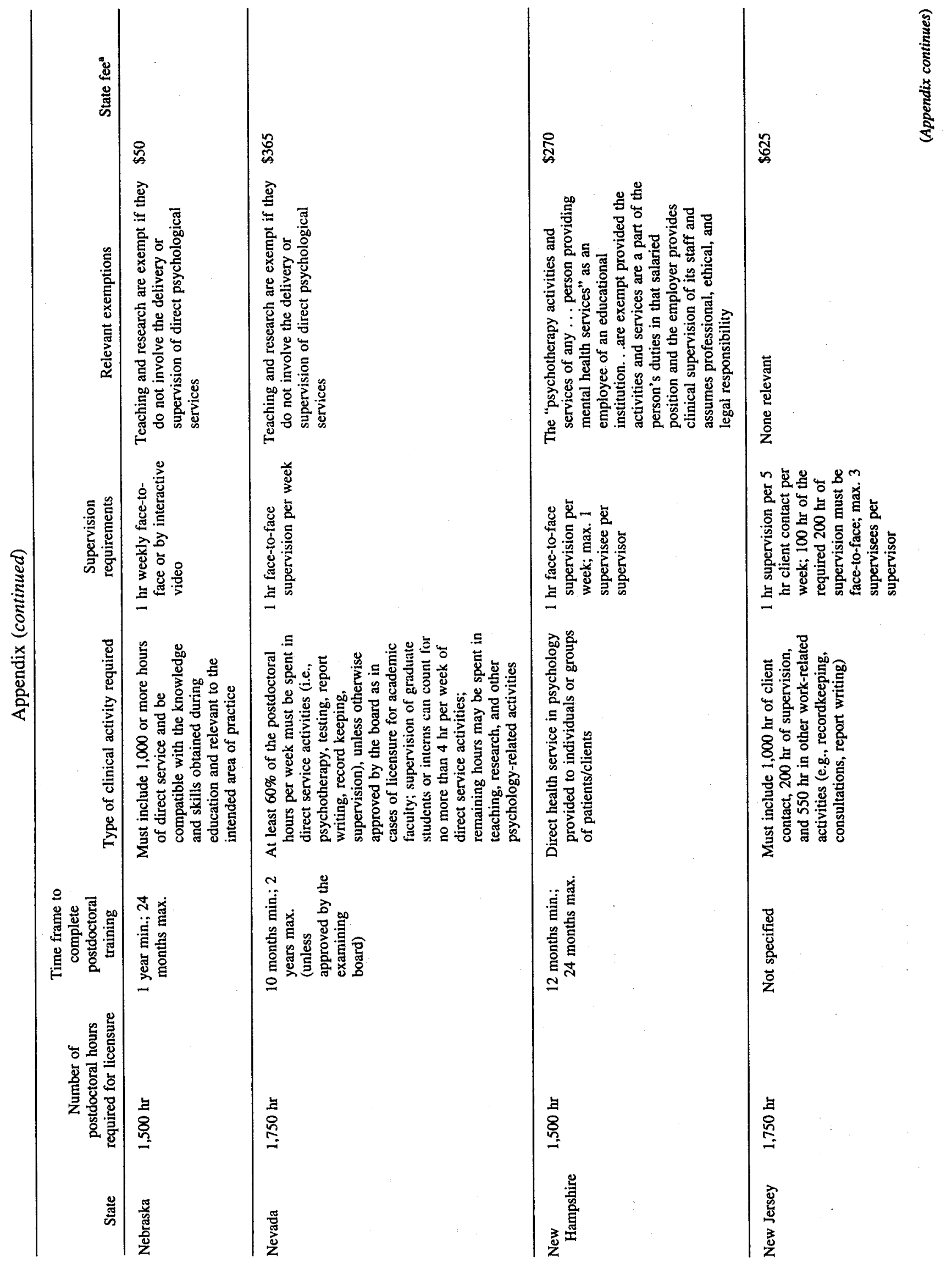




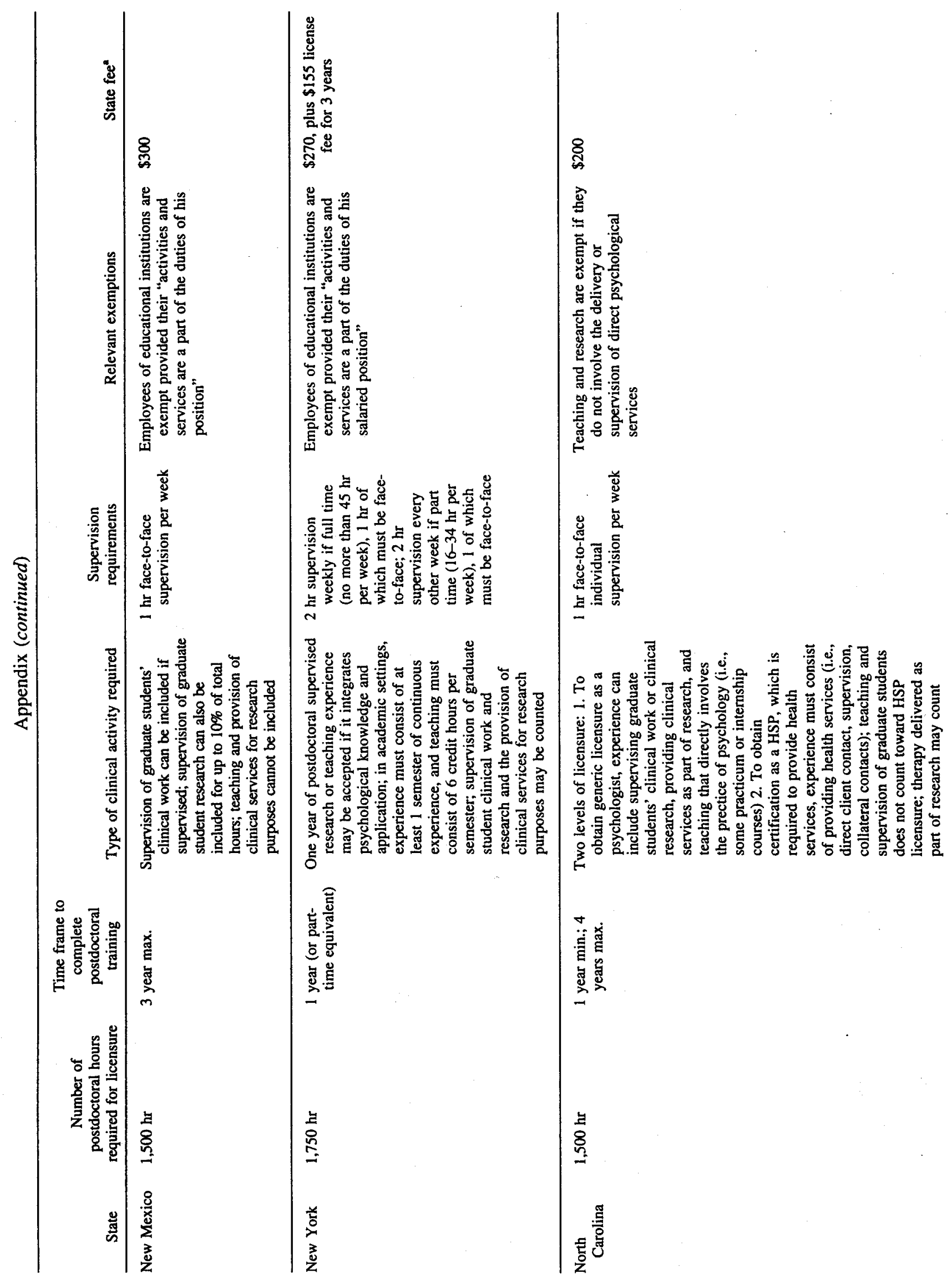




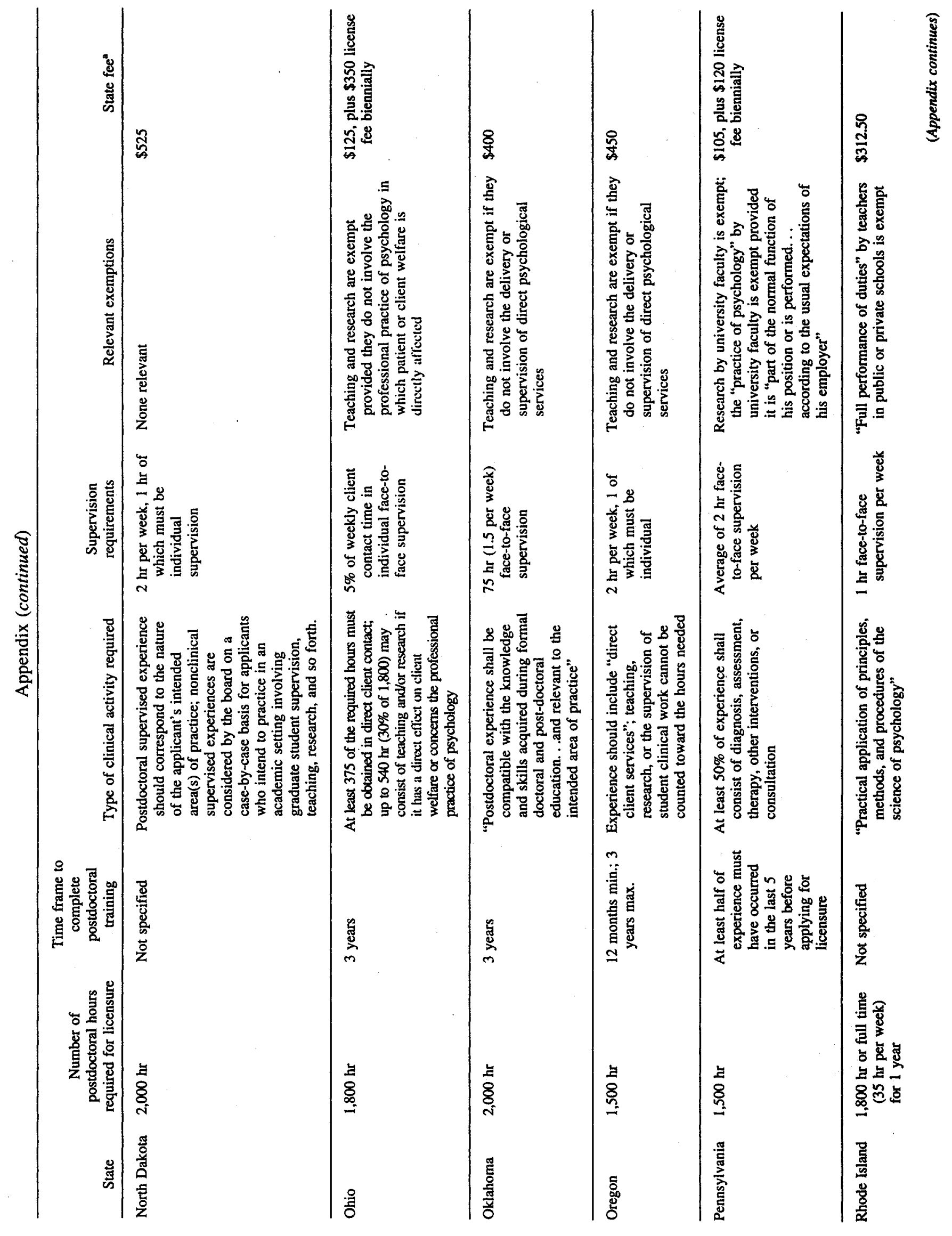




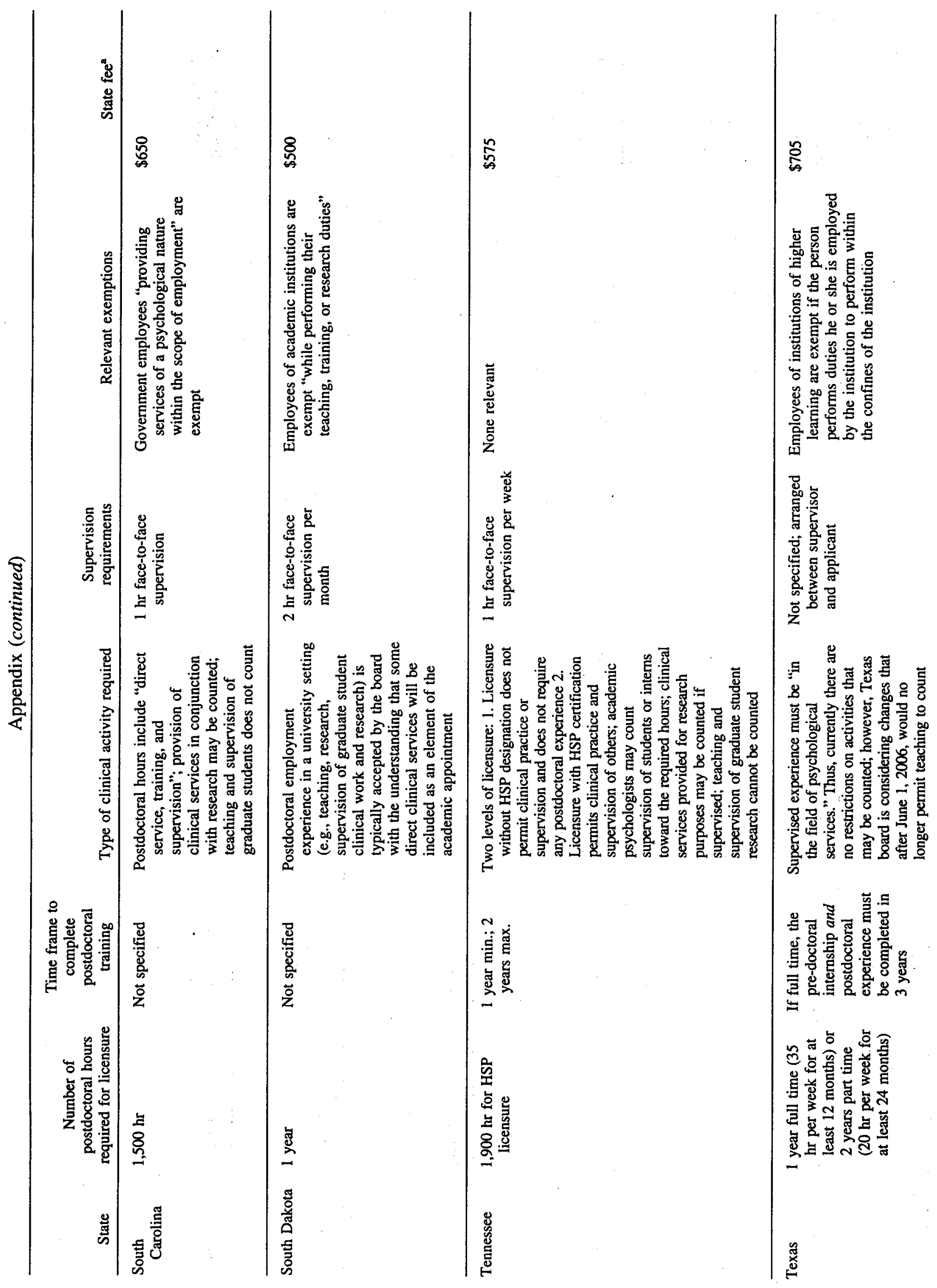




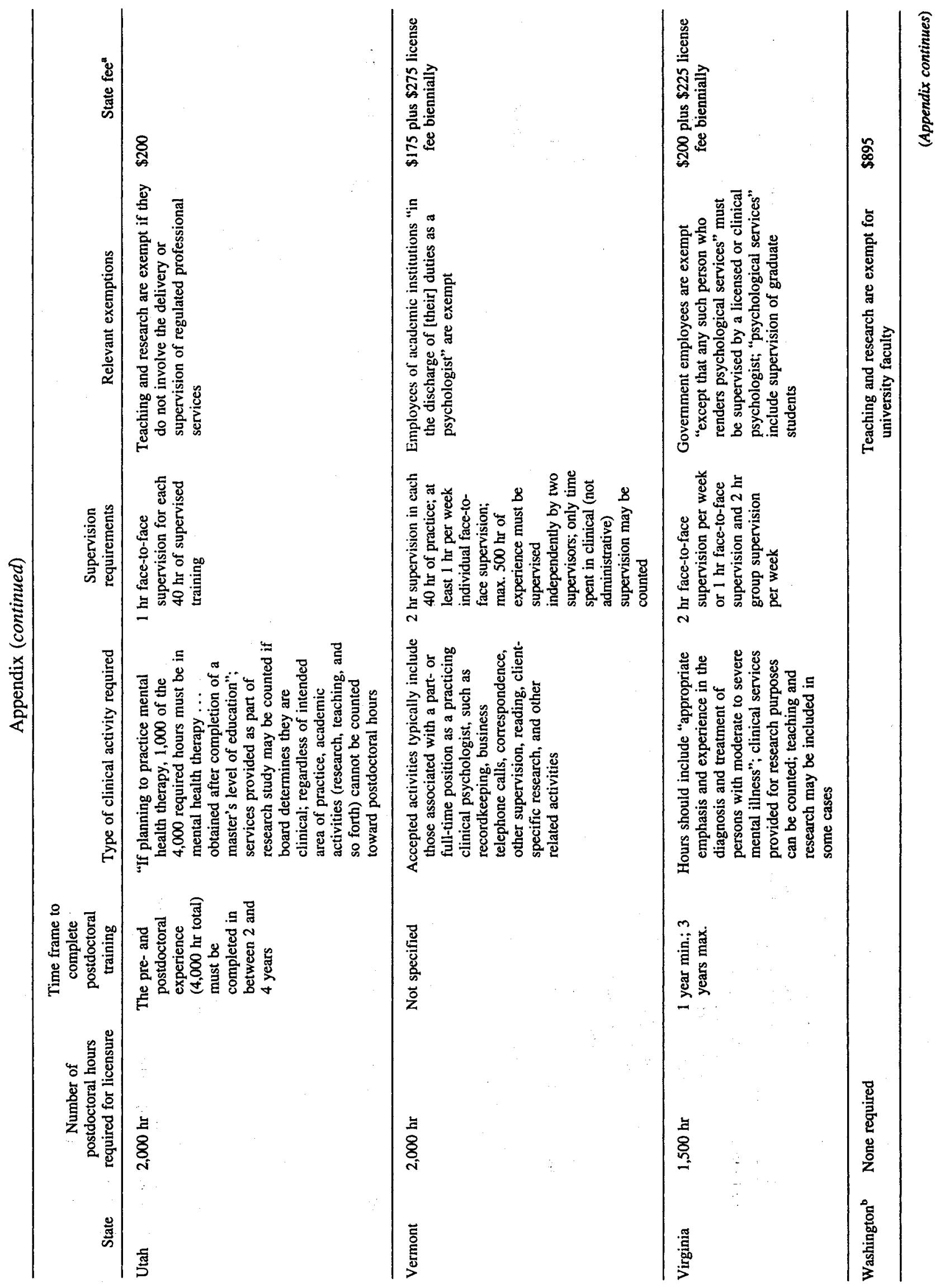




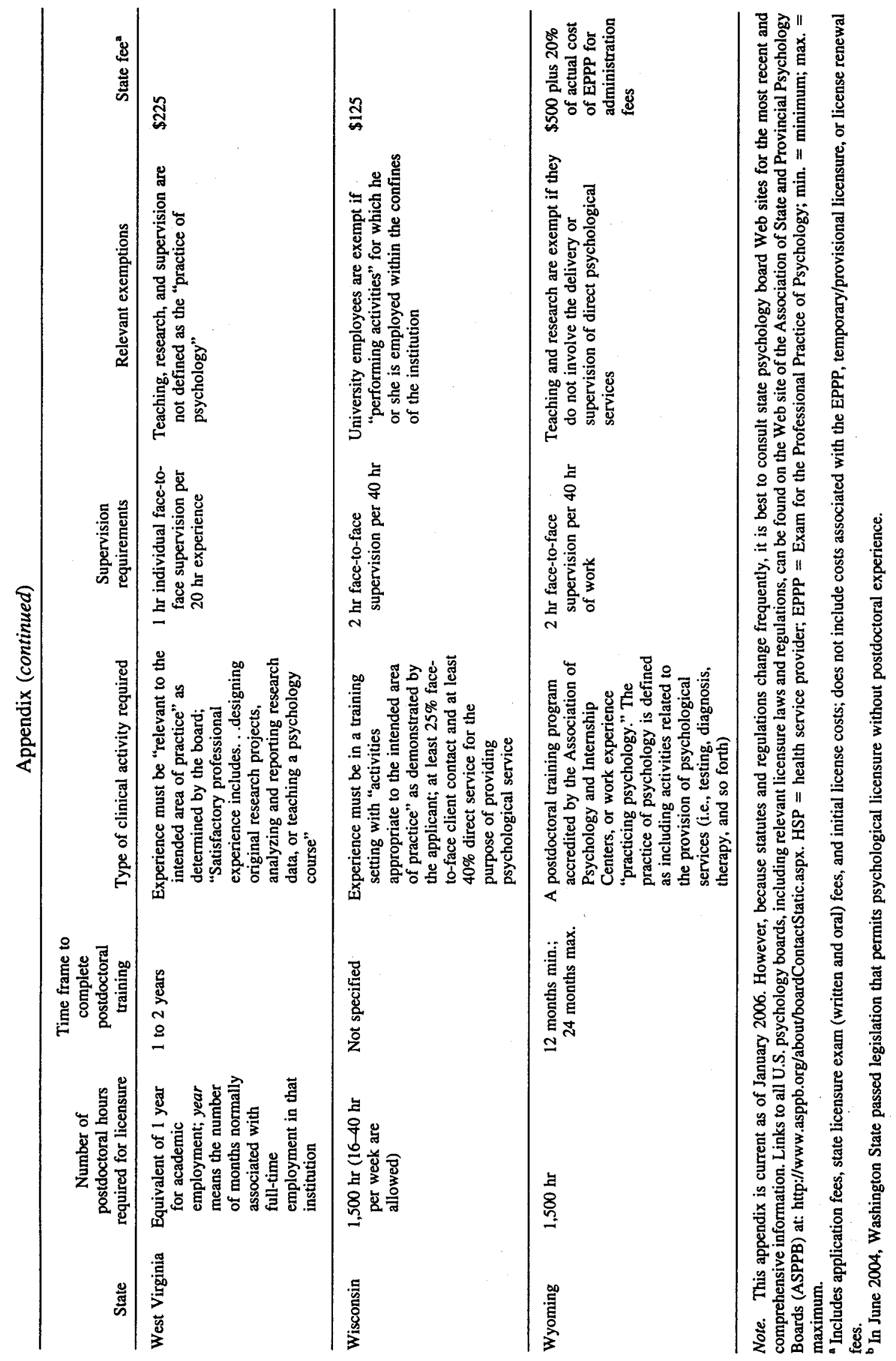

